\title{
Age-related changes in lawn phytocenoses of various species
}

\author{
Irina Khussainova ${ }^{1 *}$ \\ ${ }^{1}$ RSE "Institute of botany and phytointroduction”, Introduction Department, 050040 Almaty, \\ Kazakhstan
}

\begin{abstract}
This article presents comparative data on the study of several composite multicomponent and monocomponent lawn cenoses based on the analysis of their density and decorative score. To ensure the best stability, projective coating and decorativeness, it is important when choosing components and composing herbal mixtures to take into account their interspecific dynamics of development, pace of development and longevity. Optimum cenoses are obtained by combining species from the rhizome-bush group, slowly growing, yet more long-lived, such as Festuca rubra L., Poa pratensis L. The decorativeness of such cenoses is about 7.5 points, density about 20000 $\mathrm{pcs} / \mathrm{m}^{2}$. With age, in complex cenoses, the density of shoots increases, in monotypic ones it decreases.
\end{abstract}

\section{Introduction}

At the first stages of the scientific substantiation during the assortment selection for lawn cenoses, monocultural cenoses were considered the best. Gradually, researchers concluded that the use of herbal mixtures includes an advantage, as it increases the range of genetic diversity and increases the adaptive potential of phytocenosis cultures. In grass mixtures, the projective cover is increased, the number of weeds is reduced and the material costs for their maintenance are reduced. [1,2]. The consumption of grass mixtures is also intended to offset the difference in climatic conditions according to years. The presence of cereal species of various ecological characteristics in the grass stand ought to increase the adaptability of the grass stand to changing moisture conditions and thermal conditions, which vary greatly in accordance with years. The advantage of mixtures in comparison with single-species crops in reducing the probability of the disease occurrence and their harmfulness has also been proved [3].To determine the percentage ratio of certain groups of lawn grasses in grass mixtures, the dominance of species in certain soil and climatic conditions, the rate of their development and longevity, the rhythm of development during the growing season, and the interspecific dynamics of phytocenosis components in time are significant importance [4]. These features are widely used in modeling grass lawn mixtures. One of the most common

\footnotetext{
* Corresponding author: fhusi@yandex.ru
} 
options is a combination of species that differ in growth rate and life expectancy. Most researchers believe that herb tillering is considered to be one of the essential indicators of the vitality of a particular species growing in cenosis with other species. The maximum tillering occurs at temperatures far lower than the optimal shoot growth temperatures [5] and the optimum temperature for "cold climate" herbs is from 10 to $18^{\circ} \mathrm{C}[6,7]$.

The research aim was to study the connection of different herb species growing in multicomponent lawn cenoses of various compositions and to compare with similar monocultural grass stands based on an assessment of their tillering and decorative qualities.

\section{Materials and Methods}

\subsection{Object of study}

When creating artificial lawn phytocenoses, components of grass mixtures with programming of dominants are outlined in advance. We have compiled 4 variants of compound mixtures and 3 monocomponent variants: 1. 'Chewing's fescue' type - Festuca rubra 'Boreal' 40\%, Lolium perenne 'Score' 30\%, Poa pratensis 'Balin' 20\%, F. rubra 'Frida' 10\%; 2. 'Ryegrass' type - L. perenne 'Score' 30\%, L. perenne 'Raygaubek' 30\%, F. rubra 'Boreal' 20\%, P. pratensis 'Balin' 20\%; 3. 'Bluegrass meadow' type - $P$. pratensis 'Sobra' 60\%, F. rubra 'Boreal' 20\%, F. rubra 'Frida' 10\%, L. perenne 'Score' $10 \%$; 4. F. rubra 'Boreal' 100\%; 5. L. perenne 'Score'; 6. P. pratensis 'Balin' 100\%. The component order in the composition of grass mixtures is represented taking into account the percentage of their content in the grass mixture from larger to smaller. As a fastgrowing component, we used L. perenne. It not only adduces a high projective cover in the first year of sowing, yet it also creates micro conditions for the germination of other herbs. Accounting sites were subjected to regular haircuts (20-22 times per season).

\subsection{Methods of study}

The density of shoots is one of the main aspects of quality [8]. It has been proven that visual quality levels correlate with shoot density [9]. To determine the number of shoots per unit surface area of the soil, as one of the objective indicators of the decorative and mechanical qualities of the turf coating, a framework of $(0.1 \times 0.1) \mathrm{m}$ was used [10]. Counting was carried out twice per season - in May (at the time of active tillering) and in September (during the period of autumn tillering activation) in four repetitions. Within the above framework, the total number of shoots was calculated regardless of the type of tillering, separately the number of shoots of each species constituting the grass mixture, the number of green and yellow leaves twice a season for five years According to the proposed method of L.P. Mytsyk, the aspectual greening of the lawn was determined from a distance of 5-7 meters and an angle of 15 degrees once a year of sowing [11], whereas the projective cover was glazed annually twice a season. Sod quality assessment was carried out on a scale from 1 to 9: 1 - bad, 2 - adequate, 9 - ideal, and included color, density, disease susceptibility, uniformity, winter damage, plant vitality [12].

\subsection{Statistical methods}

Statistical analysis of the observation results, taking into account the average values and the coefficient of variation, was carried out using the Microsoft Excel 2010 application; 
LSD (Lowest Significant Difference) was used to determine the significance of differences between the data sets [13].

\section{Results}

Tests of L. perenne. in the conditions of an arid steppe zone in southeast Kazakhstan showed its nice germination energy and germination in the field, rapid development, excellent tillering in the first year of life. The dominant position of $L$. perenne will take 13 years, and then gradually begin to be replaced by slowly developing, yet more longlived species (F. rubra, P. pratensis). F. rubra and P. pratensis by type of tillering belong to the rhizome-bush group. They form a system of rosette shoots of bush nature, connected by rhizomes of different lengths [14]. Samples of F. rubra differ in the degree of formation of vegetative shoots and the type of shoots, which is taken into account when assessing the decorativeness of biotypes. Significant differences in shoot density between species and between species within species are noted [15]. Rhizome-friable bush cereals, such as F. rubra, P. pratensis, are most perfect for long-term turf coverings. Over time, these species will act as codominants. That is, their participation will depend on the climatic and soil conditions of the laid experiment place [16]. Subdominant species compile more than $10 \%$ of the number of shoots in the grass mixture. Species that compile less than $10 \%$ are classified as complementary [4].

'Chewing's fescue' type. The main dominant of the F. rubra mixture is represented in this herb mixture by two varieties from subsp. rubra and subsp. commutata. These two subspecies differ not only in the specifics of tillering, the formation of vegetative and generative shoots, seed productivity, habit, but also in appearance [17]. Promising greening occurs on the 30th day from the moment of mass shoots. Projective coverage $-83 \%$. Table 1 represents the fiveyear dynamics of grass stand development in compound grass mixtures 'Chewing's fescue' type, 'Ryegrass' type and 'Bluegrass meadow' type. Changes in the ratio of components occur gradually towards a decrease in the presence of fescue and an increase in the content of Pooideae and Ryegrass. Changes in the ratio of components are wave-like with a positive trend of an increase in the total density of grass by $20 \%$ by the fifth year of life. The maximum number of fescue shoots is observed in the fourth year of lawn life. An increase in the percentage of poa occurs only in the fifth year. A significant variation in the content of shoots of fescue (5350-18200 per $\left.\mathrm{m}^{2}\right)$ and ryegrass $\left(800-14050\right.$ per $\left.\mathrm{m}^{2}\right)$ is observed. The representative of the subspecies rubra cultivar 'Boreal' is characterized by the presence of both plagiotropic and orthotropic shoots. The subspecies commutata, to which the 'Frida' variety belongs, does not form plagiotropic shoots and increases the vegetative mass solely due to orthotropic shoots and leaves on them. The combination in the cenosis of plants with a different character allows to create a lawn with the best projective cover and decorative qualities. $P$. pratensis acts as a codominant. As a subdominant $-L$. perenne. Despite the insignificant presence of ryegrass in the first year of sowing, from the second year there has already been an increase in the content of its shoots in the grass with a maximum by the third year.

'Ryegrass' type. Some researchers reported that when seeding ryegrass mixed with $P$. pratensis and Festuca arundinacea $L$., even in a small percentage (about $10 \%$ ), ultimately, $L$. perenne dominated, despite the care measures experiments $[3,18,19]$. Other sources noted a decrease in the number of ryegrass shoots from the second year of life both in clean crops and in a mixture with other species [20]. According to A.A. Lapteva, L. perenne acts as a temporary dominant in the first 1-3 years of grass stand life [4]. In our experience, this rapidly developing species is represented by two varieties 'Score' and 'Raygaubek'. Aspective greening - on day 22 , projective coverage $-77 \%$. An increase is observed in the total density of grass by $28 \%$ by the fifth year of life due to an increase in the content of poa and festuca. 
The maximum number of ryegrass shoots is observed in the second year of the lawn's life, after which its content gradually decreases.

'Bluegrass meadow' type. $P$. pratensis will dominate, two varieties of $F$. rubra act as subdominants here, and $L$. perenne is present as a complementary species to obtain a green background more quickly. Perspective greening - on day 30 , projective cover $-80 \%$. Changes in the ratio of components occur gradually towards a decrease in the presence of ryegrass and fescue and a smooth increase in Poa content with a trend towards an increase in the total density by $19 \%$ by the fifth year of life. The maximum number of Poa shoots is observed in the fourth year of the lawn's life, after which its content gradually decreases.

Table 1. Changes in the composition of grass stands during five years of life and the main parameters of the samples

\begin{tabular}{|c|c|c|c|c|c|c|c|c|}
\hline \multirow[t]{2}{*}{ № } & \multirow{2}{*}{$\begin{array}{l}\text { Sample parameters, } \\
\qquad \mathrm{n}=9\end{array}$} & \multicolumn{4}{|c|}{ Shoots, pcs $/ \mathrm{m}^{2}$} & \multicolumn{2}{|c|}{ Leaves, pcs $/ \mathrm{m}^{2}$} & \multirow[t]{2}{*}{ Points } \\
\hline & & Festuca & Lolium & Poa & Total & Green & Yellow & \\
\hline \multirow[t]{9}{*}{1} & \multicolumn{8}{|c|}{$(50)(30)(20)^{*}$} \\
\hline & Avg & 9560 & 7330 & 1380 & 18820 & 45920 & 1390 & 7,3 \\
\hline & Max & 18200 & 14050 & 2600 & 26800 & 82550 & 2750 & 9 \\
\hline & Min & 5350 & 800 & 350 & 14200 & 32650 & 500 & 6 \\
\hline & $\sigma$ & 3930 & 3460 & 790 & 3420 & 1400 & 750 & 0,9 \\
\hline & $\mathrm{V}, \%$ & 41,1 & 47,2 & 57,6 & 18,2 & 30,5 & 53,9 & 12,9 \\
\hline & \multicolumn{8}{|c|}{ The ratio of components, $\%$} \\
\hline & 1 year & 91,5 & 5,6 & 2,8 & 100 & 100 & $6,1^{* *}$ & \\
\hline & 5year & 61,1 & 24 & 14,8 & 100 & 100 & 1,8 & \\
\hline \multirow[t]{9}{*}{2} & \multicolumn{8}{|c|}{$(20)(60)(20)$} \\
\hline & Avg & 2260 & 8520 & 3230 & 14010 & 32510 & 1230 & 6,6 \\
\hline & Max & 3900 & 15250 & 7100 & 18250 & 38700 & 2550 & 8 \\
\hline & Min & 1200 & 4700 & 1100 & 9450 & 21050 & 600 & 5 \\
\hline & $\sigma$ & 910 & 3280 & 2380 & 2870 & 5600 & 670 & 0,8 \\
\hline & $\mathrm{V}, \%$ & 40,3 & 38,5 & 73,5 & 20,5 & 17,2 & 54,2 & 12,7 \\
\hline & \multicolumn{8}{|c|}{ The ratio of components, $\%$} \\
\hline & 1 year & 13,2 & 75,8 & 11 & 100 & 100 & 9,9 & \\
\hline & 5 year & 24,8 & 30 & 45,2 & 100 & 100 & 2,7 & \\
\hline \multirow[t]{9}{*}{3} & \multicolumn{8}{|c|}{$(30)(10)(60)$} \\
\hline & Avg & 6060 & 3330 & 9120 & 18530 & 49790 & 2660 & 6,9 \\
\hline & Max & 9250 & 10200 & 17900 & 22650 & 59300 & 6000 & 8 \\
\hline & Min & 3000 & 600 & 1250 & 13150 & 32800 & 1200 & 5 \\
\hline & $\sigma$ & 1840 & 3120 & 5290 & 2660 & 7930 & 1710 & 0,9 \\
\hline & $\mathrm{V}, \%$ & 30,3 & 93,5 & 58,0 & 14,4 & 15,9 & 64,2 & 12,7 \\
\hline & \multicolumn{8}{|c|}{ The ratio of components, $\%$} \\
\hline & 1 year & 39,3 & 18,3 & 42,3 & 100 & 100 & 14,4 & \\
\hline & 5 year & 28,4 & 3,7 & 67,9 & 100 & 100 & 3,6 & \\
\hline \multicolumn{3}{|c|}{ Shoots $^{* * *}$} & \multicolumn{2}{|c|}{ Green leaves } & \multicolumn{2}{|c|}{ Yellow leaves } & \multicolumn{2}{|c|}{ Points } \\
\hline & $\mathrm{LSD}_{05}$ & $\mathrm{~d}$ & $\mathrm{LSD}_{05}$ & $\mathrm{~d}$ & $\mathrm{LSD}_{05}$ & $\mathrm{~d}$ & $\mathrm{LSD}_{05}$ & $\mathrm{~d}$ \\
\hline
\end{tabular}




\begin{tabular}{|c|c|c|c|c|c|c|c|c|}
\hline $1-2$ & 3150 & 4810 & $\mathbf{1 0 1 1 0}$ & 13420 & 640 & 160 & 0,9 & 0,7 \\
\hline $1-3$ & 3060 & 290 & 10790 & 3870 & $\mathbf{1 1 9 0}$ & 1270 & 0,9 & 0,4 \\
\hline $2-3$ & $\mathbf{2 7 7 0}$ & 4520 & $\mathbf{6 5 1 0}$ & 17290 & $\mathbf{1 1 7 0}$ & 1430 & 0,9 & 0,3 \\
\hline
\end{tabular}

Note: ${ }^{*}$ - the percentage of participation in the mixture, ${ }^{* *}$ - percentage of yellow leaves of the number of green leaves, ${ }^{* *}$ - a comparison of samples by parameters: number of shoots, number of green and yellow leaves, total decorative points, LSD with a confidence level of $95 \%, \mathrm{~d}$ - difference between the average values of samples, with $\mathrm{d} \geq$ LSD differences are significant.

Monoculture F. rubra 'Boreal'. Slowly developing grass stand. Aspective greening on the 35 th day, projective cover $76 \%$. Table 2 presents the five-year dynamics of the development of monocultural crops 'Boreal', 'Score', 'Balin'. In option 5, the maximum tillering was noted in the second year of the test of 22000 shoots $/ \mathrm{m}^{2}$. The general trend is a $15 \%$ decrease in grass density by the fifth year.

Monoculture L. perenne 'Score'. Fast growing grass stand. Promising greening - on day 26 , projective cover $-74 \%$. Changes in the number of ryegrass shoots are wave-like, regardless of the time of year, from 14400 to 28100 shoots $/ \mathrm{m}^{2}$. The maximum tillering was noted in the first year of the test of 28100 shoots $/ \mathrm{m}^{2}$. The general trend of the density of grass stands is a decrease of $53 \%$ by the fifth year.

Monoculture P. pratensis 'Balin' Slow-growing grass stand. Aspective greening - on day 35 , projective cover $80 \%$.

In this version, the maximum tillering was noted in the fourth year -14450 shoots $/ \mathrm{m}^{2}$. The decrease in density of grass by the fifth year by $2 \%$. So, when creating clean lawns from slowgrowing grasses $P$. pratensis, $F$. rubra, grass stands develop slowly including a low projective cover in the first year, so during this period they are actively populated by weeds, as a result of which their content becomes more expensive and decorativeness is lost. Comparing the data between multicomponent

Table 2. Changes in the density of monotypic grass stands during five years of life and their comparison with analogous multicomponent

\begin{tabular}{|c|c|c|c|c|c|c|c|}
\hline \multirow{2}{*}{ № } & \multirow{2}{*}{$\begin{array}{c}\text { Sample } \\
\text { parameters, } \\
\mathrm{n}=9\end{array}$} & \multicolumn{3}{|c|}{ Shoots, pcs / $\mathrm{m}^{2}$} & \multicolumn{2}{|c|}{ Leaves, $\mathrm{pcs} / \mathrm{m}^{2}$} & \multirow{2}{*}{ Points } \\
\hline & & Festuca & Lolium & Poa & Green & Yellow & \\
\hline \multirow[t]{9}{*}{4} & \multicolumn{7}{|c|}{$(100)(0)(0)^{*}$} \\
\hline & Avg & 18040 & & & 44850 & 2660 & 6,6 \\
\hline & Max & 22000 & & & 60750 & 4450 & 8 \\
\hline & Min & 14700 & & & 30100 & 1400 & 6 \\
\hline & $\sigma$ & 2330 & & & 9120 & 1010 & 0,7 \\
\hline & $\mathrm{V}, \%$ & 12,9 & & & 20,3 & 38,1 & 10,4 \\
\hline & \multicolumn{7}{|c|}{ The ratio of components, $\%$} \\
\hline & 1 year & & & & 100 & $8,8^{* *}$ & \\
\hline & 5 year & & & & 100 & 7,1 & \\
\hline \multirow[t]{4}{*}{5} & \multicolumn{7}{|c|}{$(0)(100)(0)$} \\
\hline & Avg & & 17240 & & 37420 & 1840 & 6,2 \\
\hline & Max & & 28100 & & 55000 & 4600 & 7 \\
\hline & Min & & 13200 & & 31100 & 350 & 5 \\
\hline
\end{tabular}




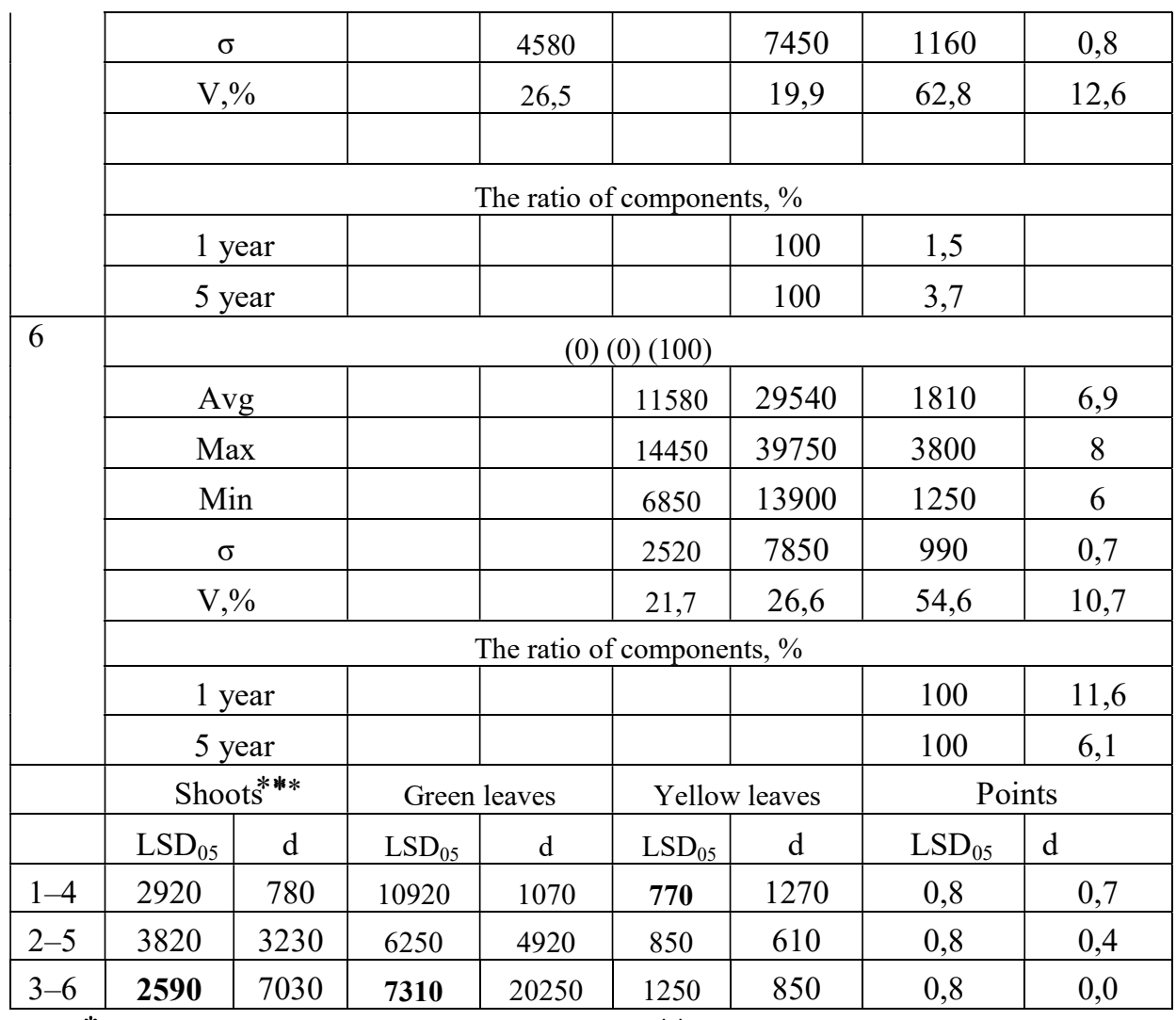

Note: ${ }^{*}$ - the percentage of participation in the mixture, ${ }^{* *}-$ the percentage of yellow leaves out of the number of green leaves, ${ }^{* *}$ - a comparison of samples in terms of the number of shoots, the number of green and yellow leaves, total decorative points, LSD with a confidence level of $95 \%, d-$ is the difference between the average values of the samples, with $d \geq$ LSD differences are significant and are highlighted in bold.

grass mixtures and monoculture, the difference can be seen in the onset of aspect greening. In 'chewing's fescue' and 'bluegrass meadow' types it is five days earlier than in the clean crops, in the' ryegrass 'type it is 4 days earlier.

\section{Discussion}

The tables show that the dynamics of changes in the content of slowly growing components like $F$. rubra and P. pratensis occurs very smoothly. So, in 'chewing's fescue' grass stand, dominated by $F$. rubra from the first year of life, the peak of its presence is observed only in the fourth year of life. In the fourth year, the maximum presence of $P$. pratensis in 'Bluegrass meadow' type grass stand is also observed. The number of shoots of Festuca, Poa, Lolium varies greatly from spring to autumn, from year to year in all tested grass mixtures. Each artificially created phytocenosis is an example of a complex, movable in time and space, yet quite flexible system. With the joint growth of species from different genera, with various life forms and various rates of development in ontogenesis in the lawn cenosis mode under conditions of competition and symbiosis, decorativeness is affected by planting density, agrotechnical care conditions, and the composition of the grass mixture. The degree of leaf destruction may indicate the state of a particular cenosis. The trend comparison of shoot 
formation of composite and monotypic cenoses reveals a stable increase in shoot density by the fifth year of life in 'chewing's fescue' type by $20 \%$, in 'ryegrass'type by $27 \%$, and in 'bluegrass meadow' type by $21 \%$. While in monotypic grass stands a gradual decrease in density is observed: in 'bluegrass meadow' $(2 \%)$, 'chewing's fescue' 'Fescue' $(15 \%)$ and, to a greater extent, in 'ryegrass' (53\%). The maximum shoot density, projective cover and a high decorative point in the 'chewing's fescue' and 'bluegrass meadow' types (7.3 and 6.9, respectively) occur due to the presence of two subspecies of $F$. rubra. Thus, complex culture phytocenoses, composed of the most compatible components, develop a denser elevated mass compared to pure crops, which is consistent with the findings of other scientists. The latter is undesirable to use for creating extensive lawn coverings due to their instability to adverse climatic conditions, diseases and low decorativeness.

\section{References}

1. V.A. Tyuldyukov, I.V. Kobozev, N.V. Parahin, Turfgrass stadies and landscaping of inhabitad territories (Moskow, 2002)

2. C.M. Donald, Adv. Agron. 15, 1-118 (1963)

3. J.H. Dunn, E.H. Ervin, B.S. Fresenburg, Hort. Science. 37, 214-217 (2002)

4. A.A. Laptev, Turfgrasses (Kiev, 1983)

5. J.B. Beard, Turfgrass Science and Culture. Prentice Hall, Engelwood Cliffs, N.J., 658 (1973)

6. Da Costa, B. Huang, Heat-stress physiology and management. Turfgrass: Biology, use and management (Agron. Monogr. ASA, CSSA and SSSA. Madison, W.I., 2013)

7. X. Liu, B. Huang, Environ. Exp. Bot. 53, 233-245 (2005)

8. B. Boller, U.K. Posselt, Fodder Crops and Amenity Grasses. Handbook of Plant Breeding. 5, 552 (2010)

9. A.H. Bruneau, A.J. Newell and F.M.E. Crossley, J. Turfgrass Sci. 76, 63-69 (2000)

10. S.P. Smelov, Establishment of objective indicators of the turf quality on airfields. 5, 65 (Moscow, 1943)

11. L.P. Mytsyk, Ecological and biological basis of the creation of turf establishment in steppe zone (Ph. D. Thesis, Biology, Dnepropetrovsk State University, 1992)

12. National Turfgrass Evaluation Programm, National perennial ryegrass test 1994. (NTEP Prog. Rep. USDA-ARS, Beltsville, MD, 1998)

13. L.G. Ryazanova, A.V. Provorchenko, I.V. Gorbunov, Fundamentals of statistical analysis of research results in gardening (Kuban State Agrarian University, Krasnodar, 2013)

14. T.I. Serebryakova, Morphogenesis of shoots and the evolution of cereal life forms (Nauka, Moskow, 1971)

15. M.J. Gooding, A.J. Newell, J. Sports Turf Res. Inst. 66, 141-148 (1990)

16. T.A. Rabotnov, Phytozenology ( Moscow, 1978)

17. A. Kvalbein, T.S. Aamlid, The grass guide (Landvik, NIBIO turfgrass research group, 2015)

18. K.L. Hunt, J.H. Dunn, Agron J. 85, 211-215 (1993)

19. T. Hsiang, K. Carey, B. He, J.E. Eggens, Intl. Turfgrass Soc. Res. J. 8, 671-679 (1997)

20. A.A. Paddubskii, T.S. Lazareva, Yu.A. Mazhaiskii, E.A. Piven', 12, 17-24 (2017) 